\title{
Association of Body Mass Index with the Risk of Incident Type 2 Diabetes, Cardiovascular Disease, and All-Cause Mortality: A Community-Based Prospective Study
}

\author{
Ji Cheol Bae ${ }^{1, *}$, Nam H. Cho ${ }^{2, *}$, Jae Hyeon Kim, Kyu Yeon Hur ${ }^{3}$, Sang-Man Jin ${ }^{3}$, Moon-Kyu Lee ${ }^{4}$ \\ ${ }^{1}$ Division of Endocrinology and Metabolism, Department of Internal Medicine, Samsung Changwon Hospital, Sungkyunkwan \\ University School of Medicine, Changwon; ${ }^{2}$ Department of Preventive Medicine, Ajou University School of Medicine, Suwon; \\ ${ }^{3}$ Division of Endocrinology and Metabolism, Department of Internal Medicine, Samsung Medical Center, Sungkyunkwan \\ University School of Medicine, Seoul; ${ }^{4}$ Division of Endocrinology and Metabolism, Department of Internal Medicine, \\ Soonchunhyang University Gumi Hospital, Soonchunhyang University College of Medicine, Gumi, Korea
}

Background: Type 2 diabetes and cardiovascular disease (CVD) are the most important sequelae of obesity and the leading cause of death. We evaluated the association between body mass index (BMI) and the risk of incident type 2 diabetes, CVD, and all-cause mortality in a prospective study of a Korean population.

Methods: The shapes of the associations were modeled by restricted cubic splines regression analysis. After categorizing all subjects $(n=8,900)$ into octiles based on their BMI levels, we estimated the hazard ratio (HR) for the association of categorized BMI levels with the risk of incident CVD and type 2 diabetes using a Cox's proportional hazard analysis.

Results: The mean age of participants was 52 years and $48 \%$ were men. Of the subjects at baseline, $39.0 \%$ of men and $45.6 \%$ of women were classified as obese (BMI $\geq 25 \mathrm{~kg} / \mathrm{m}^{2}$ ). Over a mean follow-up of 8.1 years, CVD events occurred in 509 participants; 436 died; and 1,258 subjects developed type 2 diabetes. The increased risk of incident diabetes began to be significant at BMI 23 to $24 \mathrm{~kg} / \mathrm{m}^{2}$ in both sexes (HR, 1.8). For CVD events, the risk began to increase significantly at BMI 26 to $28 \mathrm{~kg} / \mathrm{m}^{2}(\mathrm{HR}, 1.6)$. We found a reverse J-shaped relationship between BMI and all-cause mortality, with an increased risk among individuals with BMI values in lower range $\left(\mathrm{BMI}<21 \mathrm{~kg} / \mathrm{m}^{2}\right)$.

Conclusion: These results suggest that the BMI cut-off points for observed risk were varied depending on the diseases and that the BMI classification of obesity need to be revised to reflect differential risk of obesity-related diseases.

Keywords: Body mass index; Obesity; Diabetes mellitus; Cardiovascular diseases

\section{INTRODUCTION}

Obesity can be defined as an excess of body fat. Obesity raises

Received: 6 January 2020, Revised: 18 March 2020, Accepted: 14 May 2020 Corresponding author: Moon-Kyu Lee

Division of Endocrinology and Metabolism, Department of Internal Medicine, Soonchunhyang University Gumi Hospital, Soonchunhyang University College of Medicine, 179 1gongdan-ro, Gumi 39371, Korea

Tel: +82-54-468-9046, Fax: +82-54-468-9051, E-mail: leemk4132@gmail.com the risk for cardiovascular disease (CVD) through other risk factors including dyslipidemia, hypertension, hyperglycemia, and insulin resistance indicating that obesity is an underlying

Copyright $\odot 2020$ Korean Endocrine Society

This is an Open Access article distributed under the terms of the Creative Commons Attribution Non-Commercial License (https://creativecommons.org/ licenses/by-nc/4.0/) which permits unrestricted non-commercial use, distribution, and reproduction in any medium, provided the original work is properly cited.

*These authors contributed equally to this work. 
major risk factor for CVD [1]. The most widely used simple anthropometric measurement to identify obesity in clinical practice is body mass index (BMI) [2].

BMI is a simple index using person's height and weight that is commonly used to identify overweight and obesity in adults. The World Health Organization (WHO) BMI classifications of overweight (defined as BMI $\geq 25 \mathrm{~kg} / \mathrm{m}^{2}$ ) and obesity (defined as BMI $\geq 30 \mathrm{~kg} / \mathrm{m}^{2}$ ) are intended for international use; these classifications reflect increased risk for type 2 diabetes and CVD [3]. On the basis of the available data, Asians generally have a higher percentage of body fat than white Westerners with the same BMI, and have increased CVD risks at lower BMI values [4]. There is also accumulating evidence of high prevalence of type 2 diabetes and other major cardiovascular risk factors at the BMI below the level of $25 \mathrm{~kg} / \mathrm{m}^{2}$ that defines overweight in WHO classification [4-6]. For these reasons, the need for developing different BMI cut-off points for different ethnic groups has emerged, but defining obesity for Asian has long been a subject of debate $[4,7]$. As such, the WHO consultation group decided not to define BMI cut point for Asians separately. Instead, they identified potential public health action points along the BMI continuum ranging from 23.0 to $27.5 \mathrm{~kg} / \mathrm{m}^{2}$ and proposed that each country make decisions regarding the definitions of increased risk for its population [4]. In China, BMIs of 24 and $28 \mathrm{~kg} / \mathrm{m}^{2}$ are recommended as the cut-off points for overweight and obesity, respectively [8]. The Korean Society for the Study of Obesity (KSSO) has established the lower BMI thresholds of $25 \mathrm{~kg} / \mathrm{m}^{2}$ for obesity and $23 \mathrm{~kg} / \mathrm{m}^{2}$ for overweight in Koreans [9].

Type 2 diabetes and CVD are the most important sequelae of obesity and are the leading cause of death in adults $[3,10]$. We assessed prevalence of obesity and evaluated the association between BMI levels and the risk of incident type 2 diabetes, CVD, and all-cause mortality in a prospective study of a Korean population. The results were also discussed in terms of obesity criteria for Koreans adults.

\section{METHODS}

\section{The Korean Genome and Epidemiology Study-Ansan and Ansung study}

The Korean Genome and Epidemiology Study (KoGES) is an ongoing prospective population-based cohort study with the support from the National Genome Research Institute. The recruitment of patients, study design, and methods for the KoGES Ansan and Ansung study have been reported previously [10].
Briefly, 10,038 subjects (aged 40 to 69 years) were enrolled in the two different cities of Ansung and Ansan from 2001 to 2002. Since the baseline examination (2001 to 2002), biennial repeated follow-up surveys have been continued. Recently, the eighth follow-up examination (2017 to 2018) has been completed.

\section{Subjects}

Initial data were obtained from 10,038 subjects who participated in the KoGES Ansan and Ansung Study. Among these subjects, those who had previous history of CVD $(n=249)$ and those who did not undergo any follow-up surveys after the baseline recruitment (2001 to 2002) $(n=908)$ were excluded. After applying the above exclusion criteria, the number of participants eligible for the study was $8,900(4,243$ men and 4,657 women with a mean age of 52.3 years). At each visit, investigator obtained informed written consent from all participants. The study protocol was approved by the ethics committee of the Korean Center for Disease Control and Institutional Review Board of the Ajou University School of Medicine (IRB approval No. AJIRB-CRO-07-012).

\section{Study design and statistical analyses}

In this study, only data up to the fifth follow-up examination period (2011 to 2012) were analyzed. During a 12 years follow-up period, 9,130 (91\%) subjects underwent one or more follow-up examinations, and 6,117 (61\%) completed the fifth follow-up survey (2011 to 2012). The spline regression analyses were used to evaluate the association between BMI levels and the risk of incident type 2 diabetes, CVD, and all-cause mortality. Analyses were performed in a separate model by sex. The shapes of the associations between BMI and CVD, and allcause mortality were modeled by restricted cubic splines (adjusted for age, smoking, alcohol intake, and regular exercise) with four knots set at the 5th, 25th, 75th, and 95th percentiles. In males, knots were equivalent to BMI levels of 19.3, 22.2, 26.1 , and $29.1 \mathrm{~kg} / \mathrm{m}^{2}$, respectively, while the values for females were $20.0,22.6,26.9$, and $30.8 \mathrm{~kg} / \mathrm{m}^{2}$, respectively. We considered the BMI value associated with the lowest risk as the reference value; in the analysis of association with CVD, the BMI of 21.1 and $21.4 \mathrm{~kg} / \mathrm{m}^{2}$ were the reference values for men and women, respectively; for association with all-cause mortality, the reference values were set as the BMI of 27.1 and $22.2 \mathrm{~kg} / \mathrm{m}^{2}$, respectively. The plot was truncated at the 1st and the 99th percentile. After further exclusion of participants with known diabetes ( $n=1,250 ; 634$ men and 616 women) at baseline, spline regression analyses for the association with development of type 2 diabetes was conducted in the same manner as the analy- 
sis for the association with incident CVD. The BMI of 21.0 and $21.3 \mathrm{~kg} / \mathrm{m}^{2}$ were the reference values for men and women, respectively. After categorizing all subjects into octiles based on their BMI levels, we also estimated the hazard ratio (HR) for the association of categorized BMI level with the risk of incident CVD, type 2 diabetes, and all-cause mortality using a Cox's proportional hazard analysis. Statistical data analysis was performed using STATA software version 15.1 (Stata Corp., College Station, TX, USA).

\section{Definition}

A CVD event was defined as acute myocardial infarction, coronary-bypass surgery, coronary angioplasty, coronary stent insertion, angina pectoris, acute stroke, and death due to coronary disease or stroke that occurred during the follow-up period. Data on CVD event occurrence were obtained through in-depth interviews with the study participants. These interviews were repeated biennially. There were continuous attempts to contact participants who did not undergo follow-up examination by telephone or by door-to-door visit. Information about the deaths including the dates, places, and causes was obtained from the participants' family members through these contacts. The development of diabetes was assessed from the biennial follow-up examinations and diagnosed according to the criteria of American Diabetes Association (ADA): (1) plasma glucose $\geq 126 \mathrm{mg} / \mathrm{dL}$ in the fasting state; (2) plasma glucose $\geq 200 \mathrm{mg} / \mathrm{dL} 2$ hours after a $75 \mathrm{~g}$ oral glucose load; or (3) glycated haemoglobin $\geq 6.5 \%$ [11]. Also, at an in-depth interview conducted at each visit, subjects who had a history of diabetes or currently used insulin or oral anti-diabetic drugs were considered to have developed diabetes. Hypertension was defined as blood pressure greater than or equal to $140 / 90 \mathrm{~mm} \mathrm{Hg}$ or use of antihypertensive medication. We defined dyslipidemia as serum low density lipoprotein cholesterol $\geq 160 \mathrm{mg} / \mathrm{dL}$, high density lipoprotein cholesterol $<40$ $\mathrm{mg} / \mathrm{dL}$, triglycerides $\geq 200 \mathrm{mg} / \mathrm{dL}$, or use of any medication for dyslipidemia [12]. Regular exercise was defined as doing physical exercise more than three times per week.

Table 1. Baseline Characteristics

\begin{tabular}{|c|c|c|c|}
\hline Characteristic & Male $(n=4,243)$ & Female $(n=4,657)$ & Total $(n=8,900)$ \\
\hline Age, yr & $51.8 \pm 8.8$ & $52.7 \pm 9.0$ & $52.3 \pm 8.9$ \\
\hline Weight, kg & $67.4 \pm 9.8$ & $58.9 \pm 8.6$ & $63.0 \pm 10.1$ \\
\hline BMI, $\mathrm{kg} / \mathrm{m}^{2}$ & $24.2 \pm 2.9$ & $24.9 \pm 3.3$ & $24.6 \pm 3.1$ \\
\hline $\mathrm{BMI} \geq 25 \mathrm{~kg} / \mathrm{m}^{2}$ & $1,656(39.0)$ & $2,123(45.6)$ & $3,779(42.5)$ \\
\hline $\mathrm{BMI} \geq 30 \mathrm{~kg} / \mathrm{m}^{2}$ & $121(2.9)$ & $331(7.1)$ & $452(5.1)$ \\
\hline Waist circumference, $\mathrm{cm}$ & $83.6 \pm 7.6$ & $81.9 \pm 9.7$ & $82.7 \pm 8,8$ \\
\hline Percentage of body fat, $\%$ & $21.5 \pm 5.1$ & $31.6 \pm 5.5$ & - \\
\hline Diabetes & $634(14.9)$ & $616(13.2)$ & $1,123(12.6)$ \\
\hline $\mathrm{HbA1c}, \%$ & $5.81 \pm 0.94$ & $5.78 \pm 0.91$ & $5.80 \pm 0.93$ \\
\hline Fasting glucose, mg/dL & $91.5 \pm 23.9$ & $86.6 \pm 19.1$ & $88.9 \pm 21.7$ \\
\hline HOMA-IR & $1.63 \pm 1.16$ & $1.77 \pm 1.43$ & $1.70 \pm 1.31$ \\
\hline Hypertension & $1,003(23.6)$ & $1,198(25.7)$ & $2,201(24.7)$ \\
\hline Systolic blood pressure, $\mathrm{mm} \mathrm{Hg}$ & $117.5 \pm 16.5$ & $117.5 \pm 19.4$ & $117.5 \pm 18.1$ \\
\hline Dyslipidemia & $2,262(53.3)$ & $2,187(47.0)$ & $4,449(50.0)$ \\
\hline LDL-C, mg/dL & $118.0 \pm 37.5$ & $119.1 \pm 33.3$ & $118.6 \pm 35.3$ \\
\hline Triglyceride, $\mathrm{mg} / \mathrm{dL}$ & $173.4 \pm 114.8$ & $144.0 \pm 86.3$ & $158.0 \pm 101.9$ \\
\hline $\mathrm{HDL}-\mathrm{C}, \mathrm{mg} / \mathrm{dL}$ & $45.1 \pm 10.8$ & $47.4 \pm 10.9$ & $118.6 \pm 35.3$ \\
\hline Regular exercise & $762(18.0)$ & $869(18.7)$ & 1,631 (18.3) \\
\hline Current drinker & $3,005(70.8)$ & $1,192(25.6)$ & 4,197 (46.9) \\
\hline Current smoker & $2,082(49.1)$ & $162(3.5)$ & $2,244(25.2)$ \\
\hline
\end{tabular}

Values are expressed as mean \pm standard deviation or number $(\%)$.

BMI, body mass index; HbAlc, glycated haemoglobin; HOMA-IR, homeostasis model assessment of insulin resistance; LDL-C, low density lipoprotein cholesterol; HDL-C, high density lipoprotein cholesterol. 


\section{RESULTS}

The mean age of participants was 52 years and $48 \%$ were men. The mean \pm SD BMI of participants were $24.6 \pm 3.1 \mathrm{~kg} / \mathrm{m}^{2}$ (range, 14.4 to 40.2 ). Of the subjects at baseline, $39.0 \%$ of men and $45.6 \%$ of women were classified as obese as defined by the KSSO cut-off (BMI $\geq 25 \mathrm{~kg} / \mathrm{m}^{2}$ ). The proportion of participants who had diabetes was $12.6 \%(1,123$ of 8,900$)$ (Table 1$)$. Over a mean follow-up of 8.1 \pm 2.6 years, CVD events occurred in 509 participants (241 men and 268 women); 436 (293 men and 143 women) died; and 1,258 subjects (665 men and 593 women) developed type 2 diabetes. Restricted cubic spline regression analysis revealed a $\mathrm{J}$-shaped association between BMI levels and incident CVD events $(P$ value for nonlinearity $=0.045$ for men and 0.048 for women) (Fig. 1). The risk for development of CVD was lowest at BMI levels of 20 to $22 \mathrm{~kg} / \mathrm{m}^{2}$ in men and 21 to $22 \mathrm{~kg} / \mathrm{m}^{2}$ in women, and BMI levels higher than $26.0 \mathrm{~kg} / \mathrm{m}^{2}$ in men and $26.5 \mathrm{~kg} / \mathrm{m}^{2}$ in women were associated with a significantly increased risk. The overall shape of the association between BMI levels and incident diabetes demonstrated an increased risk of incident diabetes at BMI levels higher than 23.7
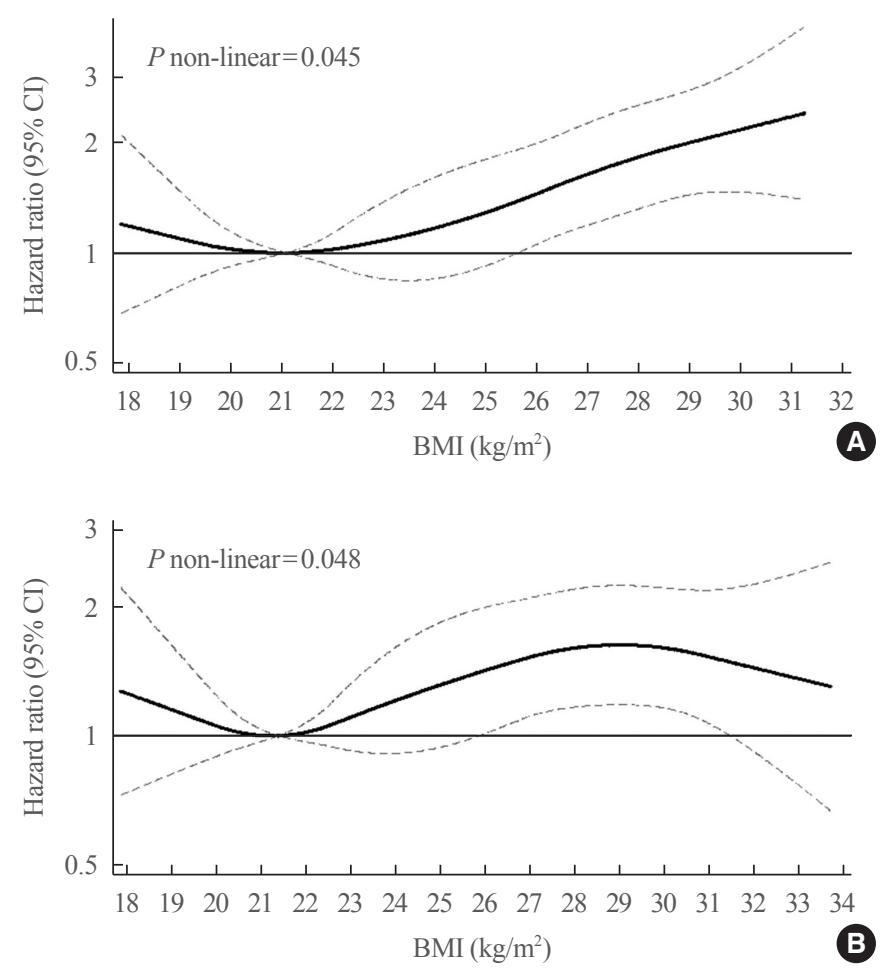

Fig. 1. The association between body mass index (BMI) level and development of cardiovascular disease. (A) Men, (B) Women. The analyses were adjusted for age, smoking, alcohol intake, and regular exercise. Dash line indicates 95\% confidence interval (CI). $\mathrm{kg} / \mathrm{m}^{2}$, with lowest risk occurring around BMI of $21 \mathrm{~kg} / \mathrm{m}^{2}$ in men $(P$ value for nonlinearity $=0.029)($ Fig. $2 \mathrm{~A})$. On the other hand, the cubic restricted spline model has shown gradually increasing HRs for incident diabetes with increasing BMI levels in women $(P$ value for nonlinearity $=0.108)($ Fig. $2 B)$. Unlike the finding on CVD events, a reverse J-shaped association was seen between BMI and the risk of death from any cause ( $P$ value for nonlinearity $=0.044$ for men and 0.082 for women) (Fig. 3 ). For men, the risk of mortality was lowest at BMI of 25 to 29 $\mathrm{kg} / \mathrm{m}^{2}$, with inverse association below, and positive association above (Fig. 3A). An increased risk of mortality was more pronounced at lower BMIs than at higher BMIs (Table 2, Fig. 3A). For women, we found inverse association below a BMI of 22.2 $\mathrm{kg} / \mathrm{m}^{2}$, while there was little evidence of association at higher BMI values (Table 2, Fig. 3B).

In Cox proportional hazards models, as compared with men with a BMI of 20.8 to $22.1 \mathrm{~kg} / \mathrm{m}^{2}$, men with a BMI of 26.2 to $27.4 \mathrm{~kg} / \mathrm{m}^{2}$ had a HR for incident CVD of 1.63 (95\% confidence interval [CI], 1.06 to 2.50). Among women, the risk of incident CVD increased at a BMI above $28.7 \mathrm{~kg} / \mathrm{m}^{2}$ with HR of 1.56 (95\% CI, 1.03 to 2.35 ) compared to women with a BMI of 21.3
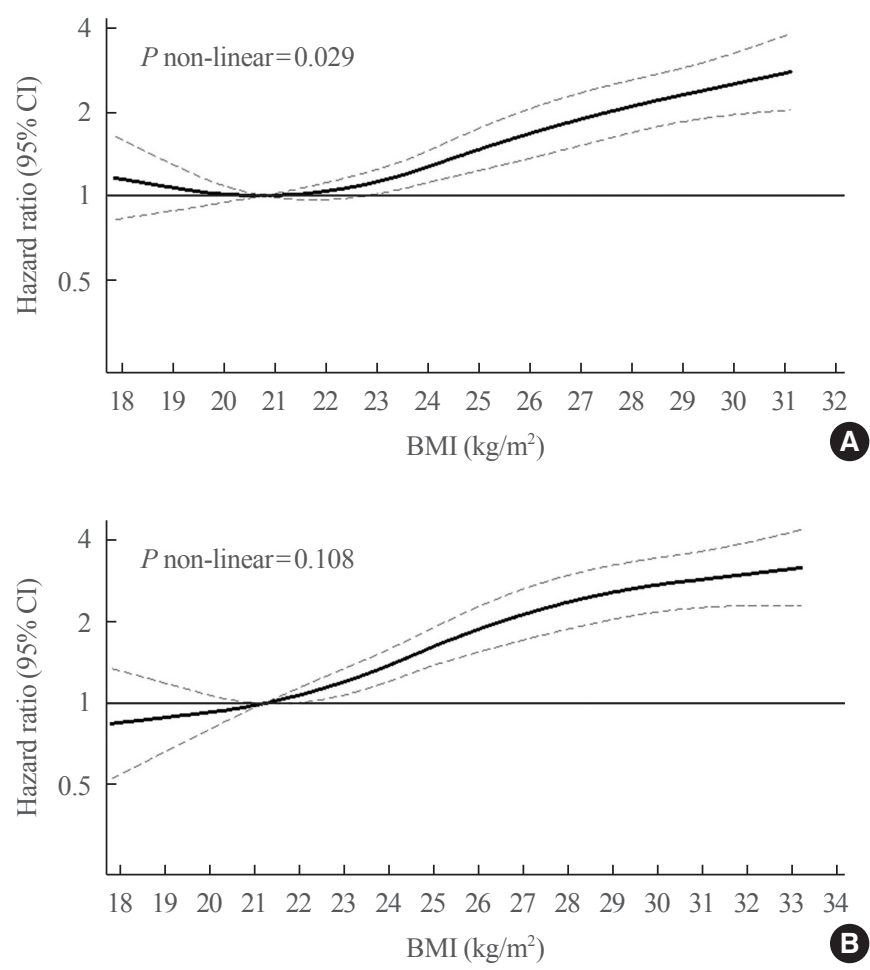

Fig. 2. The association between body mass index (BMI) level and development of type 2 diabetes. (A) Men, (B) Women. The analyses were adjusted for age, smoking, alcohol intake, and regular exercise. Dash line indicates 95\% confidence interval (CI). 


\begin{tabular}{|c|c|c|c|c|c|}
\hline BMI categories, $\mathrm{kg} / \mathrm{m}^{2}$ & Number & $\begin{array}{l}\text { No. of subjects who } \\
\text { developed diabetes }\end{array}$ & Incidence rate, $\%$ & Hazard ratio $(95 \% \mathrm{CI})^{\mathrm{a}}$ & $P$ value $^{\mathrm{b}}$ \\
\hline Men & 4,243 & 293 & 6.9 & & \\
\hline$\leq 20.7$ & 528 & 74 & 14.0 & $1.66(1.06-2.59)$ & 0.026 \\
\hline $20.8-22.1$ & 534 & 50 & 9.4 & $1.39(0.87-2.22)$ & 0.175 \\
\hline $22.2-23.2$ & 530 & 32 & 6.0 & $0.98(0.57-1.60)$ & 0.871 \\
\hline $23.3-24.1$ & 531 & 31 & 5.8 & $1.02(0.61-1.71)$ & 0.944 \\
\hline $24.2-25.0$ & 529 & 30 & 5.7 & $1.01(0.60-1.70)$ & 0.976 \\
\hline $25.1-26.1$ & 532 & 29 & 5.5 & $1.02(0.60-1.72)$ & 0.953 \\
\hline $26.2-27.4$ & 532 & 27 & 5.1 & 1 & \\
\hline$\geq 27.5$ & 527 & 20 & 3.8 & $0.87(0.41-1.34)$ & 0.380 \\
\hline Women & 4,657 & 143 & 3.1 & & \\
\hline$\leq 21.2$ & 583 & 24 & 4.1 & $1.55(0.81-2.96)$ & 0.182 \\
\hline $21.3-22.5$ & 581 & 15 & 2.6 & 1 & \\
\hline $22.6-23.5$ & 583 & 16 & 2.7 & $1.05(0.52-2.12)$ & 0.891 \\
\hline $23.6-24.5$ & 584 & 16 & 2.7 & $1.02(0.50-2.07)$ & 0.952 \\
\hline $24.6-25.5$ & 580 & 17 & 2.9 & $1.12(0.56-2.23)$ & 0.761 \\
\hline $25.6-26.6$ & 580 & 17 & 2.9 & $0.98(0.49-1.95)$ & 0.936 \\
\hline $26.7-28.4$ & 584 & 22 & 3.8 & $1.26(0.69-2.57)$ & 0.396 \\
\hline$\geq 28.5$ & 582 & 16 & 2.7 & $0.99(0.49-2.04)$ & 0.977 \\
\hline
\end{tabular}
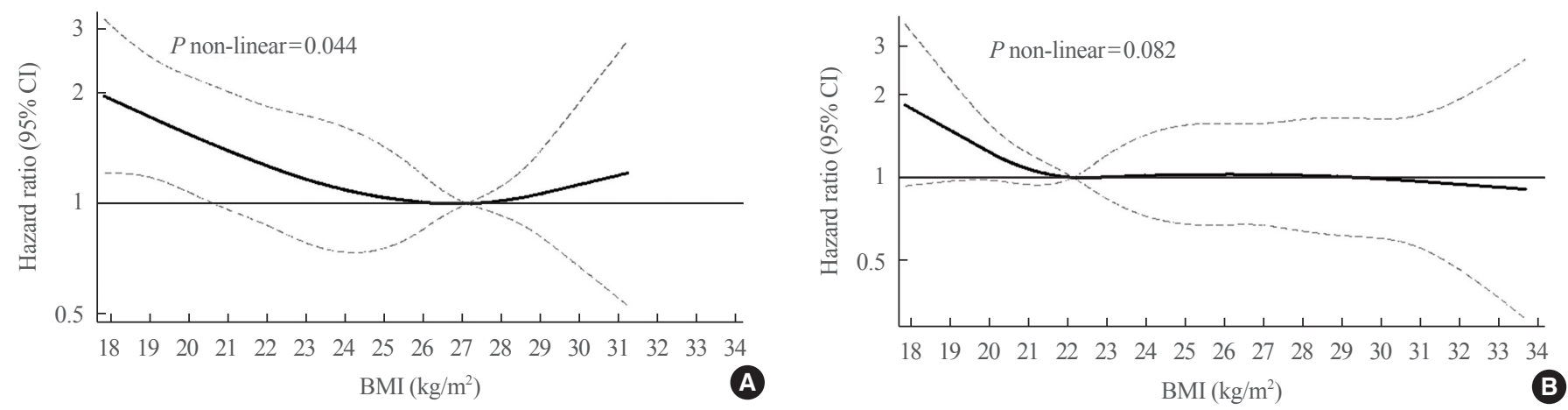

Fig. 3. The association between body mass index (BMI) level and all-cause mortality. (A) Men, (B) Women. The analyses were adjusted for age, smoking, alcohol intake, and regular exercise. Dash line indicates $95 \%$ confidence interval (CI).

to $22.5 \mathrm{~kg} / \mathrm{m}^{2}$ (Table 3). The risk of developing type 2 diabetes began to increase significantly at the BMI category of 24.2 to $25.0 \mathrm{~kg} / \mathrm{m}^{2}$ for men and 23.6 to $24.5 \mathrm{~kg} / \mathrm{m}^{2}$ for women, compared to the subjects in the lowest risk group, with HR of 1.81 ( $95 \%$ CI, 1.31 to 2.52 ) and 1.74 (95\% CI, 1.21 to 2.51 ), respectively (Table 4).

\section{DISCUSSION}

Currently, obesity is defined as a BMI $\geq 25 \mathrm{~kg} / \mathrm{m}^{2}$ in the Korean population; this criterion was set by the KSSO and recommended by the Western Pacific Regional Office (WPRO) of the WHO in 2000 [7,9]. Applying this criterion, our cohort population had an unexpectedly higher prevalence of obesity, which is close to that of United States adults. In our cohort, $39.0 \%$ of 
Table 3. Hazard Ratios for Development of Cardiovascular Disease Based on Categorized BMI Levels

\begin{tabular}{|c|c|c|c|c|c|}
\hline BMI categories, $\mathrm{kg} / \mathrm{m}^{2}$ & Number & $\begin{array}{l}\text { No. of subjects who } \\
\text { developed diabetes }\end{array}$ & Incidence rate, $\%$ & Hazard ratio $(95 \% \mathrm{CI})^{\mathrm{a}}$ & $P$ value ${ }^{\mathrm{b}}$ \\
\hline Men & 4,243 & 337 & 7.9 & & \\
\hline$\leq 20.7$ & 528 & 41 & 7.8 & $0.87(0.56-1.35)$ & 0.526 \\
\hline $20.8-22.1$ & 534 & 38 & 7.1 & 1 & \\
\hline $22.2-23.2$ & 530 & 46 & 8.7 & $1.28(0.83-1.97)$ & 0.263 \\
\hline $23.3-24.2$ & 531 & 30 & 5.6 & $0.92(0.57-1.48)$ & 0.718 \\
\hline $24.3-25.1$ & 529 & 42 & 7.9 & $1.34(0.86-2.08)$ & 0.195 \\
\hline $25.2-26.1$ & 532 & 40 & 7.5 & $1.29(0.83-2.02)$ & 0.262 \\
\hline $26.2-27.4$ & 532 & 49 & 9.2 & $1.63(1.06-2.50)$ & 0.026 \\
\hline$\geq 27.5$ & 527 & 51 & 9.7 & $1.80(1.17-2.77)$ & 0.007 \\
\hline Women & 4,657 & 356 & 7.6 & & \\
\hline$\leq 21.2$ & 583 & 36 & 6.2 & $0.90(0.57-1.43)$ & 0.653 \\
\hline $21.3-22.5$ & 581 & 37 & 6.4 & 1 & \\
\hline $22.6-23.6$ & 583 & 40 & 6.9 & $1.09(0.69-1.70)$ & 0.708 \\
\hline $23.7-24.6$ & 584 & 38 & 6.5 & $1.05(0.67-1.65)$ & 0.839 \\
\hline $24.7-25.6$ & 580 & 54 & 9.3 & $1.43(0.94-2.18)$ & 0.089 \\
\hline $25.7-26.8$ & 580 & 43 & 7.4 & $1.04(0.67-1.61)$ & 0.861 \\
\hline $26.9-28.6$ & 584 & 49 & 8.4 & $1.29(0.84-1.98)$ & 0.243 \\
\hline$\geq 28.7$ & 582 & 59 & 10.1 & $1.56(1.03-2.35)$ & 0.035 \\
\hline
\end{tabular}

BMI, body mass index; CI, confidence interval.

${ }^{a}$ Adjusted for age, smoking, alcohol intake, and regular exercise; ${ }^{b}$ Estimated from Cox proportional-hazard regression model.

men and $45.6 \%$ of women were classified as obese as defined by the KSSO cut-off (BMI $\geq 25 \mathrm{~kg} / \mathrm{m}^{2}$ ) (Supplemental Table S1); in the USA National Health and Nutrition Examination Survey (2015 to 2016), among adults aged 40 to 59 years, $40.8 \%$ of men and $44.7 \%$ of women were classified as obese based on the global WHO BMI cut-off $\geq 30 \mathrm{~kg} / \mathrm{m}^{2}$ [13]. Based on an analysis of nationally representative data from the Korea National Health and Nutrition Examination Survey (2016), the proportion of obese subjects (BMI $\geq 25 \mathrm{~kg} / \mathrm{m}^{2}$ ) was $34.8 \%$ ( $42.3 \%$ of men, $26.4 \%$ of women). In particular, the prevalence of obesity among those aged 40 to 59 years was $44 \%$ for men and $30 \%$ for women [14]. For the European population, the prevalence of obesity (BMI $\geq 30 \mathrm{~kg} / \mathrm{m}^{2}$ ) was $10 \%$ to $27 \%$ depending on the country, and the prevalence of obesity was higher in Koreans than in Europeans [15]. Scientific evidence suggests that Asians generally have a higher percentage of body fat than Westerners with the same BMI, and the risk of having CVD increases at a lower BMI value than Westerners [4]. Even so, considering the comparison with prevalence of obesity among United States and European adults, it is worth contemplating whether the current BMI cut-off point for Korean obesi- ty is too low.

In 2004, the WHO convened an expert consultation on BMI classification for the Asian population as the controversy over whether to develop different BMI cut-off points for different ethnic groups increased [4]. This consultation decided not to define cut-off points for each population separately because the available data did not indicate one clear BMI cut-off point for all Asians $[4,6,16]$. Instead, the expert consultation group designated BMI levels $\geq 23$ and $\geq 27.5 \mathrm{~kg} / \mathrm{m}^{2}$ as potential public health action points along the BMI continuum for Asian populations and proposed that each country define levels of increased risk for its population [4]. In general, BMI $\geq 25 \mathrm{~kg} / \mathrm{m}^{2}$ (defined as overweight) is considered a risk factor for diabetes, and therefore the ADA recommends testing for type 2 diabetes in adults of any age with BMI $\geq 25 \mathrm{~kg} / \mathrm{m}^{2}$ and who have additional risk factors [11]. However, for Asian American, these BMI values are lower to $\geq 23 \mathrm{~kg} / \mathrm{m}^{2}$ because BMI cut points with a sensitivity of $80 \%$ fall consistently between 23 and $24 \mathrm{~kg} / \mathrm{m}^{2}$ for nearly all Asian American subgroups [11,17]. In our study, the increased risk of incident diabetes began to be significant at around BMI 23 to $24 \mathrm{~kg} / \mathrm{m}^{2}$ in both men and women. These val- 


\begin{tabular}{|c|c|c|c|c|c|}
\hline BMI categories, $\mathrm{kg} / \mathrm{m}^{2}$ & Number & $\begin{array}{l}\text { No. of subjects who } \\
\text { developed diabetes }\end{array}$ & Incidence rate, $\%$ & Hazard ratio $(95 \% \mathrm{CI})^{\mathrm{a}}$ & $P$ value \\
\hline Men & 3,609 & 665 & 18.4 & & \\
\hline$\leq 20.7$ & 465 & 68 & 14.6 & $1.08(0.76-1.54)$ & 0.660 \\
\hline $20.8-22.1$ & 469 & 58 & 12.4 & 1 & \\
\hline $22.2-23.2$ & 462 & 74 & 16.0 & $1.29(0.91-1.81)$ & 0.141 \\
\hline $23.3-24.1$ & 438 & 69 & 15.8 & $1.29(0.92-1.82)$ & 0.153 \\
\hline $24.2-25.0$ & 438 & 89 & 20.3 & $1.81(1.31-2.52)$ & $<0.001$ \\
\hline $25.1-26.1$ & 491 & 105 & 21.4 & $1.83(1.33-2.51)$ & $<0.001$ \\
\hline $26.2-27.4$ & 414 & 92 & 22.2 & $1.98(1.43-2.73)$ & $<0.001$ \\
\hline$\geq 27.5$ & 432 & 110 & 25.5 & $2.30(1.67-3.16)$ & $<0.001$ \\
\hline Women & 4,041 & 593 & 14.7 & & \\
\hline$\leq 21.2$ & 517 & 46 & 8.9 & 1 & \\
\hline $21.3-22.5$ & 502 & 43 & 8.6 & $0.97(0.63-1.45)$ & 0.834 \\
\hline $22.6-23.5$ & 507 & 50 & 9.9 & $1.16(0.78-1.72)$ & 0.463 \\
\hline $23.6-24.5$ & 504 & 73 & 14.5 & $1.74(1.21-2.51)$ & 0.003 \\
\hline $24.6-25.5$ & 502 & 80 & 15.9 & $1.86(1.30-2.67)$ & 0.001 \\
\hline $25.6-26.6$ & 503 & 88 & 17.5 & $1.99(1.40-2.83)$ & $<0.001$ \\
\hline $26.7-28.4$ & 502 & 90 & 17.9 & $2.20(1.55-3.13)$ & $<0.001$ \\
\hline$\geq 28.5$ & 504 & 123 & 24.4 & $3.02(2.16-4.23)$ & $<0.001$ \\
\hline
\end{tabular}

ues are close to the $23 \mathrm{~kg} / \mathrm{m}^{2}$ of BMI suggested by the WHO as a potential public health action point representing increased risk for Asian populations [4] and are also close to the level given by the KSSO and the ADA as overweight $\left(\geq 23 \mathrm{~kg} / \mathrm{m}^{2}\right)[9,11]$.

Meanwhile, the risk of CVD events began to increase significantly at around BMI 26 to $28 \mathrm{~kg} / \mathrm{m}^{2}$ in both men and women; these values are above the current BMI cut-off $\left(\geq 25 \mathrm{~kg} / \mathrm{m}^{2}\right)$ for obesity in Koreans. Also, our subjects with $25 \%$ and $35 \%$ body fat (thresholds for obesity among men and women, respectively) $[1,18]$ had a BMI consistent with the median of $25.9 \mathrm{~kg} / \mathrm{m}^{2}$ (interquartile range, 24.7 to 27.0 ) in men and $26.7 \mathrm{~kg} / \mathrm{m}^{2}$ (interquartile range, 25.5 to 28.2) in women, respectively (Supplemental Table S2). In China, BMIs of $28 \mathrm{~kg} / \mathrm{m}^{2}$ are recommended as the cut-off points for obesity [8]. The Joint Statement by international diabetes organizations recommend that metabolic surgery could be an option to treat type 2 diabetes in patients with class I obesity (BMI 30.0 to $34.9 \mathrm{~kg} / \mathrm{m}^{2}$ ). In this guideline, a public health action point is applied to diabetic patients with obesity in Asian populations, recommending that a BMI value for class I obesity be reduced by $2.5 \mathrm{~kg} / \mathrm{m}^{2}$ for Asian patients to 27.5 to $32.4 \mathrm{~kg} / \mathrm{m}^{2}[19,20]$. Taken together, it may be necessary to consider raising the BMI cut-off point for Korean obesity to the international criteria of obesity for Asian population.

In our study, we found a reverse J-shaped relationship between BMI and all-cause mortality, with an increased risk among individuals with BMI values in the healthy range (BMI 18.5 to $22.9 \mathrm{~kg} / \mathrm{m}^{2}$ ). This relationship was affected by sex. For men, in particular, BMI was inversely associated with mortality up to $27 \mathrm{~kg} / \mathrm{m}^{2}$, while there was little association above $22.2 \mathrm{~kg} / \mathrm{m}^{2}$ in women. Our finding was consistent with those from the general Korean population [21-23]. In a longitudinal analysis of approximately 1.2 million Koreans, the BMI range associated with lowest mortality risk was 21.5 to $27.9 \mathrm{~kg} / \mathrm{m}^{2}$ [21]. The results from the National Health Insurance Service (NHIS) data has shown that the all-cause mortality of adults aged 45 to 75 was lowest at BMI of 24 to $28 \mathrm{~kg} / \mathrm{m}^{2}$ [22]. A reduced all-cause mortality risk was also found in a large meta-analysis of 141 studies in relation to being overweight (BMI 25 to $30 \mathrm{~kg} / \mathrm{m}^{2}$ ) and being modestly obese (BMI 30 to $35 \mathrm{~kg} / \mathrm{m}^{2}$ ) when compared with normal weight (BMI 18 to $25 \mathrm{~kg} / \mathrm{m}^{2}$ ) [24]. These findings from Korean population and meta-analysis suggest that overweight might be rather protective, indicating that current 
classification of obesity by BMI does not reflect the risk of allcause mortality. Further studies are needed to assess the association with cause-specific mortality.

Self-reported information on CVD events may have been prone to recall bias despite the in-depth nature of interview. Since all participants in our study were aged 40 to 69 years (mean 52.3土8.9) and the KoGES was conducted in two areas in South Korea, the generalizability of our results may be limited. Thus, our findings may not apply to young ages. Indeed, previous studies have shown that the BMI associated with lowest mortality risk was lower in younger individuals than in older individuals [22,23]. We did not consider abdominal adiposity which cannot be sufficiently assessed by BMI measurement. Even with subjects with the same BMI value, those with higher waist circumference may be at higher risk [25]. In addition, the medication data in this group of participants was not reflected in our analysis. The use of statin or antiplatelet drugs may have affected incident CVD events. Similarly, we do not have sufficient behavior data including physical activity and diet because these factors may change during the observation period.

Type 2 diabetes and CVD are the most important sequelae of obesity and the leading cause of death in adults $[3,10]$. In our study, the risk of incident diabetes increased significantly at BMI 23 to $24 \mathrm{~kg} / \mathrm{m}^{2}$. For CVD events, the risk began to increase significantly at BMI 26 to $28 \mathrm{~kg} / \mathrm{m}^{2}$. An increased risk of mortality was more evident at lower BMI range than current cutpoint for obesity and this association was sex-specific. The BMI cut-off points for observed risk were varied depending on the diseases and not consistent with universal cut-off values for obesity. These results suggest that the BMI classification of obesity need to be revised to reflect differential risk of obesity-related diseases.

\section{CONFLICTS OF INTEREST}

No potential conflict of interest relevant to this article was reported.

\section{ACKNOWLEDGMENTS}

This work was supported by the Research Program funded by the Korea Centers for Disease Control and Prevention (found 2001-347-6111-221, 2002-347-6111-221, 2003-347-6111-221, 2004-E71001-00, 2005-E71001-00, 2006-E71005-00, 2006E71006-00, 2007-E71001-00, 2007-E71003-00, 2008-E7100100, 2008-E71005-00, 2009-E71002-00, 2009-E71007-00, 2010-
E71001-00, 2010-E71004-00, 2011-E71004-00, 2011-E7100800, 2012-E71008-00, 2012-E71005-00). This work was partially supported by the Soonchunhyang University Research Fund. The funding source had no role in the design and conduct of the study; in the collection, management, analysis, and interpretation of the data; or in the decision to submit the manuscript for publication. The authors thank all the staff who made this study possible.

\section{AUTHOR CONTRIBUTIONS}

Conception or design: J.C.B. Acquisition, analysis, or interpretation of data: J.C.B., N.H.C., J.H.K., K.Y.H., S.M.J. Drafting the work or revising: J.C.B. Final approval of the manuscript: N.H.C., J.H.K., K.Y.H., S.M.J., M.K.L.

\section{ORCID}

Ji Cheol Bae https://orcid.org/0000-0002-4763-5797

Nam H. Cho https://orcid.org/0000-0003-4187-0929

Moon-Kyu Lee https://orcid.org/0000-0002-8728-7184

\section{REFERENCES}

1. Grundy SM. Obesity, metabolic syndrome, and cardiovascular disease. J Clin Endocrinol Metab 2004;89:2595-600.

2. Rao G, Powell-Wiley TM, Ancheta I, Hairston K, Kirley K, Lear SA, et al. Identification of obesity and cardiovascular risk in ethnically and racially diverse populations: a scientific statement from the American Heart Association. Circulation 2015;132:457-72.

3. Seidell JC, Kahn HS, Williamson DF, Lissner L, Valdez R. Report from a Centers for Disease Control and Prevention Workshop on use of adult anthropometry for public health and primary health care. Am J Clin Nutr 2001;73:123-6.

4. WHO Expert Consultation. Appropriate body-mass index for Asian populations and its implications for policy and intervention strategies. Lancet 2004;363:157-63.

5. Ko GT, Chan JC, Cockram CS, Woo J. Prediction of hypertension, diabetes, dyslipidaemia or albuminuria using simple anthropometric indexes in Hong Kong Chinese. Int J Obes Relat Metab Disord 1999;23:1136-42.

6. Deurenberg-Yap M, Chew SK, Lin VF, Tan BY, van Staveren WA, Deurenberg P. Relationships between indices of obesity and its co-morbidities in multi-ethnic Singapore. Int J Obes Relat Metab Disord 2001;25:1554-62. 
7. World Health Organization. Regional Office for the Western Pacific. The Asia-Pacific perspective: redefining obesity and its treatment. Sydney: Health Communications Australia; 2000. https://apps.who.int/iris/handle/10665/206936.

8. Chen C, Lu FC; Department of Disease Control Ministry of Health, PR China. The guidelines for prevention and control of overweight and obesity in Chinese adults. Biomed Environ Sci 2004;17 Suppl:1-36.

9. Kim MK, Lee WY, Kang JH, Kang JH, Kim BT, Kim SM, et al. 2014 Clinical practice guidelines for overweight and obesity in Korea. Endocrinol Metab (Seoul) 2014;29:405-9.

10. Bae JC, Cho NH, Suh S, Kim JH, Hur KY, Jin SM, et al. Cardiovascular disease incidence, mortality and case fatality related to diabetes and metabolic syndrome: a communitybased prospective study (Ansung-Ansan cohort 2001-12). J Diabetes 2015;7:791-9.

11. American Diabetes Association. 2. Classification and diagnosis of diabetes: standards of medical care in diabetes2019. Diabetes Care 2019;42(Suppl 1):S13-28.

12. Korean Society of Lipidology and Atherosclerosis. Dyslipidemia fact sheets in Korea, 2018 [Internet]. Seoul: Korean Society of Lipidology and Atherosclerosis; 2018 [cited 2020 May 27]. Available from: https://www.lipid.or.kr/bbs/?code=fact sheet.

13. Hales CM, Carroll MD, Fryar CD, Ogden CL. Prevalence of obesity among adults and youth: United States, 20152016 [Internet]. Atlanta: Centers for Disease Control and Prevention; 2017 [cited 2020 May 27]. Available from: https:/www.cdc.gov/nchs/data/databriefs/db288.pdf.

14. Division of Chronic Disease Control, Korea Centers for Disease Control and Prevention. Korea Health Statistics 2016: Korea National Health and Nutrition Examination Survey [Internet]. Cheongju: KCDC; c2018 [cited 2020 May 27]. Available from: https://knhanes.cdc.go.kr/knhanes/sub04/ sub04_03.do.

15. Organization for Economic Cooperation and Development. Obesity update 2017 [Internet]. Paris: OECD; 2017 [cited 2020 May 27]. Available from: http://www.oecd.org/els/
health-systems/Obesity-Update-2017.pdf.

16. Deurenberg P, Deurenberg-Yap M. Validity of body composition methods across ethnic population groups. Forum Nutr 2003;56:299-301.

17. Hsu WC, Araneta MR, Kanaya AM, Chiang JL, Fujimoto W. BMI cut points to identify at-risk Asian Americans for type 2 diabetes screening. Diabetes Care 2015;38:150-8.

18. Dickey RA, Bartuska DG, Bray GW, Callaway CW, Davidson ET, Feld S, et al. AACE/ACE position statement on the prevention, diagnosis, and treatment of obesity. Endocr Pract 1998;4:297-350.

19. American Diabetes Association. 8. Obesity management for the treatment of type 2 diabetes: standards of medical care in diabetes-2019. Diabetes Care 2019;42(Suppl 1):S81-9.

20. Rubino F, Nathan DM, Eckel RH, Schauer PR, Alberti KG, Zimmet PZ, et al. Metabolic surgery in the treatment algorithm for type 2 diabetes: a joint statement by international diabetes organizations. Diabetes Care 2016;39:861-77.

21. Jee SH, Sull JW, Park J, Lee SY, Ohrr H, Guallar E, et al. Body-mass index and mortality in Korean men and women. N Engl J Med 2006;355:779-87.

22. Yi SW, Ohrr H, Shin SA, Yi JJ. Sex-age-specific association of body mass index with all-cause mortality among 12.8 million Korean adults: a prospective cohort study. Int J Epidemiol 2015;44:1696-705.

23. Lee EY, Lee YH, Yi SW, Shin SA, Yi JJ. BMI and all-cause mortality in normoglycemia, impaired fasting glucose, newly diagnosed diabetes, and prevalent diabetes: a cohort study. Diabetes Care 2017;40:1026-33.

24. Flegal KM, Kit BK, Orpana H, Graubard BI. Association of all-cause mortality with overweight and obesity using standard body mass index categories: a systematic review and meta-analysis. JAMA 2013;309:71-82.

25. Sahakyan KR, Somers VK, Rodriguez-Escudero JP, Hodge DO, Carter RE, Sochor O, et al. Normal-weight central obesity: implications for total and cardiovascular mortality. Ann Intern Med 2015;163:827-35. 